\title{
Nonalcoholic fatty liver disease is a negative risk factor for prostate cancer recurrence
}

\author{
Won-Mook Choi ${ }^{1, *}$, Jeong-Hoon Lee ${ }^{1, *}$, Jung-Hwan Yoon', Cheol Kwak ${ }^{2}$, \\ Young Ju Lee ${ }^{2}$, Young Youn Cho', Yun Bin Lee', Su Jong Yu', Yoon Jun Kim', \\ Hyeon Hoe Kim ${ }^{2}$, Hyo-Cheol Kim ${ }^{3}$, Sung Yong $\mathrm{Cho}^{4}$, Seung Bae Lee ${ }^{4}$, \\ Hyeon Jeong ${ }^{4}$, Chung Yong Kim ${ }^{1}$ and Hyo-Suk Lee ${ }^{1}$ \\ Departments of ${ }^{1}$ Internal Medicine and Liver Research Institute, ${ }^{2}$ Urology and ${ }^{3}$ Radiology, \\ Seoul National University College of Medicine, 28 Yeongeon-dong, Jongno-gu, Seoul 110-744, \\ Republic of Korea \\ ${ }^{4}$ Department of Urology, Seoul Metropolitan Government-Seoul National University Boramae Medical Center, \\ Seoul, Republic of Korea \\ ${ }^{*}$ (W-M Choi and J-H Lee contributed equally to this work)
}

Correspondence should be addressed to J-H Yoon or C Kwak Emails yoonjh@snu.ac.kr or mdrafael@snu.ac.kr

\begin{abstract}
Nonalcoholic fatty liver disease (NAFLD) is closely related to the metabolic syndrome, which is associated with an increased risk of various malignancies. In this study, we investigated the association between NAFLD and prostate cancer biochemical recurrence (BCR) after radical prostatectomy. Consecutive prostate cancer patients who underwent radical prostatectomy were enrolled from two hospitals in Korea and randomly assigned to the training $(n=147)$ or validation set $(n=146)$. The presence of NAFLD, BMI, preoperative prostate-specific antigen, and histological findings including Gleason score (GSC) were analyzed in regard to their association with BCR. NAFLD was diagnosed based on ultrasonography or unenhanced computed tomography images. BCR-free survival rates were calculated using the KaplanMeier method. In the training set, $32(21.8 \%)$ patients developed BCR during a median follow-up period of 51 (inter-quartile range, 35-65) months. In the multivariate analysis, the presence of NAFLD (hazard ratio (HR), $0.36 ; 95 \% \mathrm{Cl}, 0.14-0.97 ; P=0.04$ ) was an independent negative predictive factor of BCR after adjustment for pathological GSC. Applied to the validation set, the presence of NAFLD maintained its prognostic value for longer time-to-BCR (HR, 0.17; 95\% Cl, 0.06-0.49; $P=0.001)$. In the subgroup analysis of patients with NAFLD, NAFLD fibrosis score was a single independent negative predictor for $\mathrm{BCR}(\mathrm{HR}, 0.54 ; 95 \% \mathrm{Cl}$, $0.30-0.98 ; P=0.04)$. Our study demonstrated that NAFLD may play a protective role against $B C R$ after radical prostatectomy for prostate cancer. Further study is warranted to elucidate the mechanism of protective effect in patients with NAFLD.
\end{abstract}

\section{Key Words \\ - nonalcoholic fatty liver disease \\ - prostate cancer \\ - radical prostatectomy \\ - biochemical recurrence}

Endocrine-Related Cancer (2014) 21, 343-353

\section{Introduction}

Nonalcoholic fatty liver disease (NAFLD) is recognized as the most common cause of chronic liver disease: it has a

http://erc.endocrinology-journals.org DOI: $10.1530 / E R C-14-0036$
(C) 2014 Society for Endocrinology Printed in Great Britain reported prevalence of $30 \%$ in the Unites States adult population (Torres \& Harrison 2008). In Korea as well, the 
prevalence of NAFLD has increased steadily and has been reported to be $16.1-27.2 \%$ due to the adoption of a Western lifestyle; thus, it has become an important healthcare issue (Kim et al. 2004, Park et al. 2006).

NAFLD is regarded as a hepatic manifestation of the metabolic syndrome because it is closely related to insulin resistance, obesity, type 2 diabetes mellitus (DM), and dyslipidemia (Angulo 2002). Obesity and metabolic syndrome are believed to increase the risk of various malignancies including endometrium, kidney, gallbladder, breast, and colon cancers (Van Gaal et al. 2006). However, the relationship of obesity or metabolic syndrome to prostate cancer risk has remained controversial. Although several studies investigating the association between obesity and prostate cancer showed conflicting results, a recent meta-analysis has concluded that obesity is associated with increased risk of prostate cancer-specific mortality and biochemical recurrence (BCR) after radical prostatectomy in prostate cancer patients (Cao \& Ma 2011). As the 5-year risk of clinical progression in men with BCR ranged from 27 to $60 \%$ and BCR typically precedes metastatic progression and prostate cancerspecific mortality by a median of 8 and 13 years, respectively, following radical prostatectomy (Pound et al. 1999), it has a clinical significance and is widely used as a critical surrogate marker for disease recurrence. While a number of studies regarding the association between metabolic syndrome and prostate cancer showed inconsistent results (Håheim et al. 2006, Tande et al. 2006, Martin et al. 2009), type 2 DM was consistently associated with a reduced risk of prostate cancer (Kasper \& Giovannucci 2006, Kasper et al. 2009, Lawrence et al. 2013).

Since NAFLD is strongly associated with metabolic syndrome, type $2 \mathrm{DM}$, and obesity and its association with prostate cancer is still unclear, we aimed to investigate the relationship between the presence of NAFLD and BCR of prostate cancer after radical prostatectomy.

\section{Subjects and methods}

\section{Patients}

We included 841 consecutive localized prostate cancer patients treated with radical prostatectomy from two different university-affiliated hospitals: Seoul National University Hospital (Seoul, Korea), between January 2005 and December 2008, and Seoul Metropolitan Government, Seoul National University Boramae Medical Center (Seoul, Korea), between February 2004 and November 2010.
The inclusion criteria were as follows: i) follow-up for $>24$ months after radical prostatectomy; ii) pathological stage of pT2 or pT3; iii) absence of distant metastasis; iv) availability of complete data regarding pathological stage and margin status; and v) availability of clinical information and abdominal ultrasonography (US) or computed tomography (CT) images to diagnose NAFLD. We excluded patients with double-primary cancers, those with evidence of liver disease of other etiologies besides NAFLD (i.e., seropositivity for hepatitis B surface antigen or anti-hepatitis C virus antibody, excessive alcohol consumption $>20 \mathrm{~g} /$ day, medications known to precipitate fatty liver during the previous 6 months, and other causes of liver disease, such as Wilson's disease or hemochromatosis), and patients who were treated with neoadjuvant hormone therapy, or who failed to achieve prostate-specific antigen (PSA) nadir $<0.1 \mathrm{ng} / \mathrm{ml}$ after radical prostatectomy. A total of 293 patients remained for analysis and were randomly assigned, in a 1:1 ratio, to the training set $(n=147)$ and the validation set $(n=146)$.

\section{Endpoints and assessments}

The primary end-point was time-to-BCR. BCR was defined as two consecutive PSA levels $\geq 0.2 \mathrm{ng} / \mathrm{ml}$. Time-to-BCR was measured from the date of radical prostatectomy until the date of BCR defined as the date of the first PSA level that was $0.2 \mathrm{ng} / \mathrm{ml}$ or greater. Patients without BCR were censored at the date of the last recorded PSA level. The follow-up after radical prostatectomy consisted of measurement of serum PSA levels: every 3 months during the first year, when negative; every 6 months during the second year; and then annually. Imaging studies were carried out when deemed necessary. In the subgroup analysis according to the risk group, patients were categorized as having low, intermediate, or high-risk disease using the D'Amico risk stratification system: low risk - clinical stage $\mathrm{T} 1 \mathrm{c}$ or $\mathrm{T} 2 \mathrm{a}$, preoperative PSA $\leq 10 \mathrm{ng} / \mathrm{ml}$, and biopsy Gleason score (GSc) $\leq 6$; intermediate risk - clinical stage T2b or $10<$ preoperative PSA $\leq 20 \mathrm{ng} / \mathrm{ml}$, or biopsy GSc 7; and high risk - clinical stage T2c or preoperative PSA $\geq 20 \mathrm{ng} / \mathrm{ml}$, or biopsy GSc 8-10 (D'Amico et al. 1998). In another subgroup analysis with patients who were diagnosed as having NAFLD, NAFLD fibrosis score, the simple noninvasive scoring system composed of six readily available variables (age, BMI, hyperglycemia, platelet count, albumin, AST:ALT ratio), was used to evaluate the effects of hepatic fibrosis on prostate cancer BCR (Angulo et al. 2007).

Published by Bioscientifica Ltd. 
NAFLD was diagnosed based on clinical information and US or unenhanced CT images of the liver. Hepatic ultrasonographies were performed by experienced radiologists unaware of clinical data. The severity of echogenicity was graded as follows: grade 0 - normal echogenicity; grade 1 - slight, diffuse increase in fine echoes in the liver parenchyma with normal visualization of diaphragm and intrahepatic vessel borders; grade 2 - moderate, diffuse increase in fine echoes with slightly impaired visualization of intrahepatic vessels and diaphragm; grade 3 - marked increase in fine echoes with poor or nonvisualization of the intrahepatic vessel borders, diaphragm, and posterior right lobe of the liver (Saadeh et al. 2002). Unenhanced CT image acquisition through the liver was performed during a single breath hold and NAFLD was diagnosed according to the severity of hepatic fatty infiltration or the measurement of liver attenuation (in housefield unit (HU)) using a standard region of interest (ROI) technique as described below. First, the severity of hepatic fatty infiltration was graded as follows: grade 0 - normal; grade 1 - liver attenuation slightly less than spleen; grade 2 - more pronounced difference between liver and spleen and intrahepatic vessels not seen or slightly higher attenuation than liver; grade 3 - markedly reduced liver attenuation with sharp contrast between liver and intrahepatic vessels (grade 1-3 were diagnosed as NAFLD) (Saadeh et al. 2002). Second, mean unenhanced liver attenuation was obtained by averaging eight $1.5 \mathrm{~cm}^{2}$ circular ROIs placed in Couinaud segments V-VIII, and the threshold of $48 \mathrm{HU}$ was used to diagnose the presence of NAFLD (Pickhardt et al. 2012). All imaging studies were reviewed by an experienced radiologist (H-C K, with over 10 years of experience) who was unaware of the patient's clinical information.

Reviewed clinical and pathological data consisted of age, weight, BMI, the presence of DM, the presence of metabolic syndrome, the presence of NAFLD, preoperative PSA level, surgical technique (open retropubic vs laparoscopic), the presence and type of adjuvant treatment, pathological GSc (divided into score $\leq 6$, score $=7$, and score $=8-10$ ), pathological T stage (pT2 vs pT3) composed with organ-confined status, presence of extraprostatic extension, or seminal vesicle invasion and lymph-node status. Metabolic syndrome was defined using the criteria established by National Cholesterol Education Program Expert Panel on the Detection, Evaluation and Treatment of High Blood Cholesterol in Adults (Adult Treatment Panel (ATP) III) (Expert Panel on Detection, Evaluation, and Treatment of High Blood Cholesterol in Adults 2001). In order to accommodate the available study data, specific
ATP III criteria were modified; BMI $>25 \mathrm{~kg} / \mathrm{m}^{2}$ was used as the criterion for abdominal obesity as measures of waist circumference were unavailable. Pathological stages were classified according to the 2010 American Joint Committee on Cancer TNM staging system (Edge \& Compton 2010).

The study conformed to the ethical guidelines of the World Medical Association Declaration of Helsinki and was approved by the Institutional Review Boards of each center.

\section{Statistical analysis}

We compared the baseline clinical and pathological characteristics using the $\chi^{2}$ test for categorical and the Student's $t$-test or the Mann-Whitney $U$ test for continuous variables. Patients' age, weight, BMI, preoperative serum PSA level, and follow-up duration were evaluated as continuous variables, while others were considered to be categorical variables. The BCR-free survival rates were estimated by the Kaplan-Meier method and compared with the log-rank test. Cox proportional hazard regression analysis was used to evaluate independent risk factors for BCR. Variables with $P<0.20$ in the univariate Cox regression analysis were preceded to multivariate analysis using forward stepwise selection. All analyses were conducted using PASW 18.0K (SPSS, Inc.), and $P$ values of $<0.05$ were considered to be statistically significant.

\section{Results}

\section{Baseline clinical and pathological characteristics}

The baseline characteristics of the study population are shown in Table 1. Patients in both sets had similar baseline characteristics. The median follow-up duration was 51.0 months (inter-quartile range (IQR), 35.0-65.0 months) in the training set and 51.0 months (IQR, 33.8-62.0 months) in the validation set.

Among the 147 patients included in the training set, 51 patients were diagnosed as having NAFLD (the NAFLD group), while 96 patients were not (the non-NAFLD group). Patients in the NAFLD group were younger and exhibited significantly higher BMI and weight compared with the non-NAFLD group. Otherwise, no statistically significant differences for clinical or pathological findings were observed between the two groups. In the validation set, 51 patients were diagnosed as having NAFLD and 95 patients were not. Patient with NAFLD showed significantly higher BMI, weight, and presence of

Published by Bioscientifica Ltd 
Table 1 Baseline characteristics of the study population

\begin{tabular}{|c|c|c|c|}
\hline & $\begin{array}{l}\text { Training set } \\
\quad(n=147)\end{array}$ & $\begin{array}{l}\text { Validation set } \\
\quad(n=146)\end{array}$ & $\boldsymbol{P}$ \\
\hline Age (years) & $66(61-70)$ & $67(62-72)$ & 0.17 \\
\hline BMI $\left(\mathrm{kg} / \mathrm{m}^{2}\right)$ & $24.3(22.3-26.1)$ & $24.3(22.0-26.3)$ & 0.64 \\
\hline Weight (kg) & $66.0(60.6-73.0)$ & $66.7(59.1-73.8)$ & 0.92 \\
\hline $\mathrm{DM}$ & & & 0.44 \\
\hline Yes & $26(17.7 \%)$ & $21(14.4 \%)$ & \\
\hline No & $121(82.3 \%)$ & $125(85.6 \%)$ & \\
\hline Metabolic syndrome & & & 0.23 \\
\hline Yes & $25(17.0 \%)$ & $20(13.7 \%)$ & \\
\hline No & $76(51.7 \%)$ & $90(61.6 \%)$ & \\
\hline Unknown & $46(31.3 \%)$ & $36(24.7 \%)$ & \\
\hline Alcohol & & & 0.97 \\
\hline Never & $105(71.4 \%)$ & $104(71.2 \%)$ & \\
\hline Current/former & $42(28.6 \%)$ & $42(28.8 \%)$ & \\
\hline NAFLD & & & 0.97 \\
\hline Yes & $51(34.7 \%)$ & $51(34.9 \%)$ & \\
\hline No & $96(65.3 \%)$ & $95(65.1 \%)$ & \\
\hline Preoperative PSA (ng/ml) & $6.8(5.0-10.7)$ & $7.3(5.1-11.2)$ & 0.62 \\
\hline $\begin{array}{l}\text { Follow-up (months) } \\
\text { BCR }\end{array}$ & $51.0(35.0-65.0)$ & $51.0(33.8-62.0)$ & $\begin{array}{l}0.69 \\
0.65\end{array}$ \\
\hline Yes & $32(21.8 \%)$ & $35(24.0 \%)$ & \\
\hline No & $115(78.2 \%)$ & $111(76.0 \%)$ & \\
\hline Surgery & & & 0.28 \\
\hline Open & $94(63.9 \%)$ & $102(69.9 \%)$ & \\
\hline Laparoscopic & $53(36.1 \%)$ & $44(30.1 \%)$ & \\
\hline Adjuvant treatment & & & 0.28 \\
\hline Active surveillance & $113(76.9 \%)$ & $109(74.7 \%)$ & \\
\hline ADT & $21(14.3 \%)$ & $29(19.9 \%)$ & \\
\hline $\mathrm{ADT}+\mathrm{RT}$ & $13(8.8 \%)$ & $8(5.5 \%)$ & \\
\hline $\begin{array}{l}\text { Pathological Gleason } \\
\text { score }\end{array}$ & & & 0.19 \\
\hline$<7$ & $53(36.1 \%)$ & $41(28.1 \%)$ & \\
\hline 7 & $80(54.4 \%)$ & $83(56.8 \%)$ & \\
\hline$>7$ & $14(9.5 \%)$ & $22(15.1 \%)$ & \\
\hline Pathological staging & & & 0.59 \\
\hline pT2 & $99(67.3 \%)$ & $94(64.4 \%)$ & \\
\hline pT3 & $48(32.7 \%)$ & $52(35.6 \%)$ & \\
\hline Surgical margins & & & 0.68 \\
\hline Positive & $50(34.0 \%)$ & $53(36.3 \%)$ & \\
\hline Negative & $97(66.0 \%)$ & $93(63.7 \%)$ & \\
\hline Extracapsular extension & & & 0.97 \\
\hline Yes & $47(32.0 \%)$ & $47(32.2 \%)$ & \\
\hline No & $100(68.0 \%)$ & $99(67.8 \%)$ & \\
\hline Invasion seminal vesicles & & & 0.98 \\
\hline Yes & $15(10.2 \%)$ & $15(10.3 \%)$ & \\
\hline No & $132(89.8 \%)$ & $131(89.7 \%)$ & \\
\hline Lymph node dissection & $41(27.9 \%)$ & $52(35.6 \%)$ & 0.16 \\
\hline Positive lymph node & $6(4.1 \%)$ & $5(3.4 \%)$ & 0.77 \\
\hline
\end{tabular}

Data presented as median (IQR) or number (\%). DM, diabetes mellitus; NAFLD, nonalcoholic fatty liver disease; PSA, prostate specific antigen; BCR, biochemical recurrence; ADT, androgen-deprivation therapy; RT, radiation therapy.

type 2 DM and metabolic syndrome, otherwise no significant differences between the two groups were observed (Table 2).

\section{Time-to-BCR}

In the training set, a total of $32(21.8 \%)$ patients developed BCR after radical prostatectomy. Figure 1A presents Kaplan-Meier curves for the time-to-BCR with patients stratified by the presence of NAFLD. The BCR-free survival rates at 5 years were $88.5 \%$ in the NAFLD group and $69.9 \%$ in the non-NAFLD group. The NAFLD group showed significantly longer time-to-BCR compared with patients without NAFLD (hazard ratio (HR), 0.33; 95\% CI, 0.16$0.69 ; P=0.02$ by log-rank test; Fig. $1 \mathrm{~A})$. In the validation set, $35(24.0 \%)$ patients developed BCR after radical prostatectomy. The BCR-free survival rates at 5 years were $92.1 \%$ in the NAFLD group and $66.1 \%$ in the nonNAFLD group. The NAFLD group exhibited significantly longer time-to-BCR compared with non-NAFLD group (HR, 0.22; 95\% CI, 0.11-0.43; P=0.001; Fig. 1B).

In the multivariate Cox analysis of training set, the presence of NAFLD (HR, 0.36; 95\% CI, 0.14-0.97; $P=0.04$ ) and pathological GSc (score 7 vs score $\leq 6$ : HR, 3.22; $95 \%$ CI, $1.21-8.59 ; P=0.02$ and score $8-10$ vs score $\leq 6$ : HR, 6.93; 95\% CI, 2.16-22.16; $P=0.001)$ was independent predictive factors for BCR after adjustment for pathological T stage (pT2 vs pT3), positive surgical margin, and positive lymph node. The presence of DM or metabolic syndrome or BMI was not a significant predictive factor for BCR after radical prostatectomy with univariate analysis. In the multivariate Cox analysis of validation set, the presence of NAFLD (HR, 0.17; 95\% CI, 0.06-0.49; $P=0.001$ ), as well as pathological GSc (score 8-10 vs score $\leq 6$ : HR, 4.44; 95\% CI, 1.39-14.21; $P=0.01)$ and positive surgical margin (HR, 3.03; 95\% CI, 1.52-6.01; $P=0.002$ ), was an independent predictive factor for $\mathrm{BCR}$; however, the presence of DM or BMI failed to show any prognostic value with univariate analysis. In the validation set, the presence of metabolic syndrome was preceded to multivariate Cox analysis due to $P<0.20$ in the univariate analysis, which failed to show statistical significance after adjustment for other covariables other than the presence of NAFLD (Table 3).

\section{Subgroup analyses according to the D'Amico risk group and NAFLD fibrosis score}

In the subgroup analysis of the whole study population according to D'Amico risk stratification, 89 (30.4\%) patients belonged to the low-risk group, 105 (35.8\%) patients belonged to the intermediate-risk group, and 99 (33.8\%) patients belonged to the high-risk group. The association between the presence of NAFLD and timeto-BCR remained significant in patients in the D'Amico high-risk group $(P=0.001 ;$ Fig. 2C). Patients in the D'Amico low- or intermediate-risk group also showed similar trends; however, the difference was not statistically significant ( $P=0.20$ and 0.07 respectively; Fig. $2 \mathrm{~A}$ and $\mathrm{B}$ ).

A total of 102 patients with NAFLD were divided into two groups according to NAFLD fibrosis score at the cutoff score of -1.455 , which could exclude advanced fibrosis

Published by Bioscientifica Ltd. 
Table 2 Clinical and pathological characteristics of patients in training set and validation set

\begin{tabular}{|c|c|c|c|c|c|c|}
\hline & \multicolumn{3}{|c|}{ Training set $(n=147)$} & \multicolumn{3}{|c|}{ Validation set $(n=146)$} \\
\hline & $\operatorname{NAFLD}(+)(n=51)$ & $\operatorname{NAFLD}(-)(n=96)$ & $P$ & $\operatorname{NAFLD}(+)(n=51)$ & $\operatorname{NAFLD}(-)(n=95)$ & $P$ \\
\hline Age (years) & $64(59-68)$ & $67(62-71)$ & 0.04 & $65(61-69)$ & $67(63-72)$ & 0.06 \\
\hline BMI $\left(\mathrm{kg} / \mathrm{m}^{2}\right)$ & $26.0(24.6-27.1)$ & $23.3(21.6-25.2)$ & $<0.001$ & $25.6(23.8-27.0)$ & $24.0(21.0-25.1)$ & $<0.001$ \\
\hline Weight (kg) & $73.0(66.4-77.0)$ & $63.5(58.6-68.8)$ & $<0.001$ & $71.9(65.8-76.9)$ & $64.2(56.7-71.9)$ & $<0.001$ \\
\hline DM & & & 0.37 & & & 0.01 \\
\hline Yes & $11(21.6 \%)$ & $15(15.6 \%)$ & & $13(25.5 \%)$ & $8(8.4 \%)$ & \\
\hline No & $40(78.4 \%)$ & $81(84.4 \%)$ & & $38(74.5 \%)$ & $87(91.6 \%)$ & \\
\hline Metabolic syndrome & & & 0.53 & & & 0.02 \\
\hline Yes & $11(21.6 \%)$ & $14(14.6 \%)$ & & $12(23.5 \%)$ & $8(8.4 \%)$ & \\
\hline No & $24(47.1 \%)$ & $52(54.2 \%)$ & & $25(49.0 \%)$ & $65(68.4 \%)$ & \\
\hline Unknown & $16(31.4 \%)$ & $30(31.3 \%)$ & & $14(27.5 \%)$ & $22(23.2 \%)$ & \\
\hline \multicolumn{7}{|l|}{ Drugs $^{a}$} \\
\hline Statins & $5(13.2 \%)$ & $8(11.6 \%)$ & 0.81 & $4(10.5 \%)$ & $5(6.5 \%)$ & 0.48 \\
\hline ACEI & $2(5.3 \%)$ & $3(4.3 \%)$ & 1.00 & - & - & \\
\hline ARB & $8(21.1 \%)$ & $15(21.7 \%)$ & 0.93 & $8(21.1 \%)$ & $15(19.5 \%)$ & 0.84 \\
\hline Alcohol & & & 0.87 & & & 0.80 \\
\hline Never & $36(70.6 \%)$ & $69(71.9 \%)$ & & $37(72.5 \%)$ & $67(70.5 \%)$ & \\
\hline Current/former & $15(29.4 \%)$ & $27(28.1 \%)$ & & $14(27.5 \%)$ & $28(29.5 \%)$ & \\
\hline Preoperative PSA (ng/ml) & $6.4(5.1-10.9)$ & $7.1(4.9-10.7)$ & 0.94 & $6.5(4.8-9.6)$ & $7.9(5.3-12.1)$ & 0.14 \\
\hline Surgery & & & 0.83 & & & 0.81 \\
\hline Open & $32(62.7 \%)$ & $62(64.6 \%)$ & & $35(68.6 \%)$ & $67(70.5 \%)$ & \\
\hline Laparoscopic & $19(37.3 \%)$ & $34(35.4 \%)$ & & $16(31.4 \%)$ & $28(29.5 \%)$ & \\
\hline Adjuvant treatment & & & 0.13 & & & 0.63 \\
\hline Active surveillance & $44(86.3 \%)$ & $69(71.9 \%)$ & & $37(72.5 \%)$ & $72(75.8 \%)$ & \\
\hline ADT & $5(9.8 \%)$ & $16(16.7 \%)$ & & $12(23.5 \%)$ & $17(17.9 \%)$ & \\
\hline $\mathrm{ADT}+\mathrm{RT}$ & $2(3.9 \%)$ & $11(11.5 \%)$ & & $2(3.9 \%)$ & $6(6.3 \%)$ & \\
\hline Pathological Gleason score & & & 0.06 & & & 0.31 \\
\hline$<7$ & $18(35.3 \%)$ & $35(36.5 \%)$ & & $18(35.3 \%)$ & $23(24.2 \%)$ & \\
\hline 7 & $32(62.7 \%)$ & $48(50.0 \%)$ & & $25(49.0 \%)$ & $58(61.1 \%)$ & \\
\hline$>7$ & $1(2.0 \%)$ & $13(13.5 \%)$ & & $8(15.7 \%)$ & $14(14.7 \%)$ & \\
\hline Pathological staging & & & 0.22 & & & 0.67 \\
\hline pT2 & $31(60.8 \%)$ & $68(70.8 \%)$ & & $34(66.7 \%)$ & $60(63.2 \%)$ & \\
\hline pT3 & $20(39.2 \%)$ & $28(29.2 \%)$ & & $17(33.3 \%)$ & $35(36.8 \%)$ & \\
\hline Surgical margins & & & 0.18 & & & 0.21 \\
\hline Positive & $21(41.2 \%)$ & $29(30.2 \%)$ & & $22(43.1 \%)$ & $31(32.6 \%)$ & \\
\hline Negative & $30(58.8 \%)$ & $67(69.8 \%)$ & & $29(56.9 \%)$ & $64(67.4 \%)$ & \\
\hline Extracapsular extension & & & 0.32 & & & 0.20 \\
\hline Yes & $19(37.3 \%)$ & $28(29.2 \%)$ & & $13(25.5 \%)$ & $34(35.8 \%)$ & \\
\hline No & $32(62.7 \%)$ & $68(70.8 \%)$ & & $38(74.5 \%)$ & $61(64.2 \%)$ & \\
\hline Invasion seminal vesicles & & & 0.09 & & & 0.66 \\
\hline Yes & $2(3.9 \%)$ & $13(13.5 \%)$ & & $6(11.8 \%)$ & $9(9.5 \%)$ & \\
\hline No & $49(96.1 \%)$ & $83(86.5 \%)$ & & $45(88.2 \%)$ & $86(90.5 \%)$ & \\
\hline Positive lymph node & $1(2.0 \%)$ & $5(5.2 \%)$ & 0.67 & $3(5.9 \%)$ & $2(2.1 \%)$ & 0.34 \\
\hline
\end{tabular}

Data presented as median (IQR) or number (\%). NAFLD, nonalcoholic fatty liver disease; DM, diabetes mellitus; ACEI, angiotensin-converting enzyme inhibitor; ARB, angiotensin receptor blocker; PSA, prostate-specific antigen; ADT, androgen-deprivation therapy; RT, radiation therapy.

${ }^{a}$ Missing $n=40$ in the training set and 31 in the validation set because of unknown status of drug history.

with $90 \%$ sensitivity and $60 \%$ specificity. In total, $9(8.8 \%)$ patients developed BCR after radical prostatectomy. The BCR-free survival rates at 5 years were $84.4 \%$ in the lower NAFLD fibrosis score group and $97.8 \%$ in the higher NAFLD fibrosis score group. The lower NAFLD fibrosis score group showed significantly longer time-to-BCR compared with the higher NAFLD fibrosis score group $(P=0.04)$ (Fig. 3). In the multivariate Cox analysis, NAFLD fibrosis score, when treated as a continuous variable, was a single independent predictor for BCR (HR, 0.54; 95\% CI, $0.30-0.98 ; P=0.04)$.

\section{Discussion}

The present study showed for the first time that the presence of NAFLD may be protective against BCR after radical prostatectomy for prostate cancer. Moreover, this is the first study showing that NAFLD may play a protective 

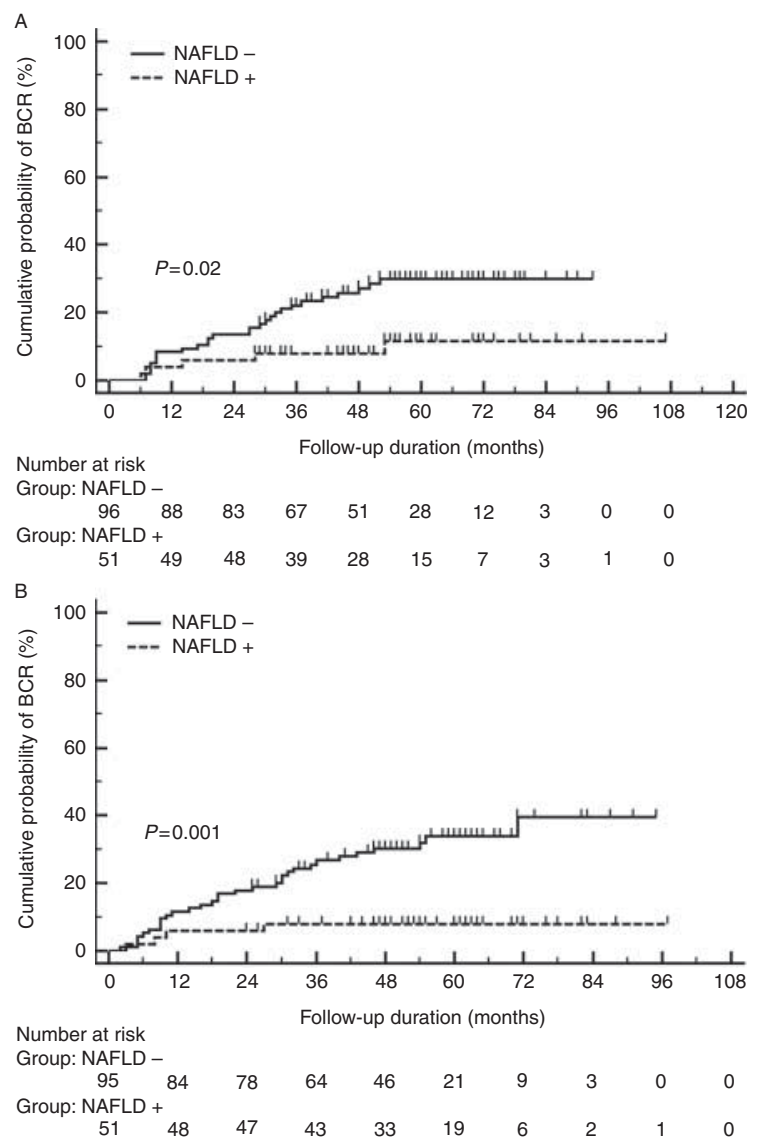

Figure 1

Time-to-BCR according to the presence of NAFLD. (A) Training set. (B) Validation set.

role against any other cancers to the best of our knowledge. Pathological GSc and/or positive surgical margin were also independent risk factors for BCR; however, the presence of DM and BMI failed to show any prognostic value in multivariate analyses of both training and validation sets. In the subgroup analyses according to D'Amico risk group, patients belonged to the high-risk group showed significant association between NAFLD and prostate cancer BCR, but patients belonged to the low or intermediate group showed similar trends without statistical significance. When NAFLD patients were stratified according to NAFLD fibrosis score, we found that the severity of fibrosis had significant correlation with BCR. In other words, it could be inferred that the risk of BCR decreased as NAFLD progressed to nonalcoholic steatohepatitis or cirrhosis with histological progression of fibrosis.

The possible mechanisms mediating the effects of NAFLD on prostate cancer BCR after radical prostatectomy are as follows. First, insulin, insulin resistance, and insulin-like growth factor 1 (IGF1) may play a critical role in the association of the NAFLD to prostate cancer BCR. Insulin is a potent mitogenic and anti-apoptotic factor, which induces potent growth effects on the prostate; furthermore, DNA polymorphisms in the insulin gene may be associated with increased prostate cancer risk (Hsing et al. 2007). A prospective case-cohort study in non-diabetic men showed that elevated fasting levels of serum insulin, but not glucose levels, appeared to be associated with a high risk of prostate cancer (Albanes et al. 2009). Insulin resistance is the most reproducible factor in the development of NAFLD (Marchesini et al. 1999); it may limit insulin actions and lead to protection against prostate cancer. An in vitro study showed that IGF1 promotes growth of primary prostate cell cultures and human prostate cancer cell lines (De Nunzio et al. 2012). In other studies, transgenic mice overexpressing human IGF1 in basal epithelial cells of the prostate were reported to develop prostate carcinoma at a high rate (DiGiovanni et al. 2000), and mice with global or liver-specific inactivation of IGF1 were associated with reduced prostate size and androgen-dependent prostate growth (Svensson et al. 2008). In addition, a meta-analysis of 42 observational studies demonstrated that elevated circulating IGF1 levels were significantly associated with prostate cancer risk (odds ratio, 1.21; 95\% CI, 1.07-1.36) (Rowlands et al. 2009). The liver is the main site of circulating IGF1 in humans (Jones \& Clemmons 1995), and an increasing body of evidence has suggested that NAFLD is associated with low circulating levels of IGF1 (Arturi et al. 2011, Fusco et al. 2012). Thus, low circulating levels of IGF1 in NAFLD could explain to some extent why NAFLD is negatively associated with prostate cancer BCR after radical prostatectomy. Second, it is well accepted that prostate cancer is a testosterone-dependent malignancy. Recent observational studies have showed that a low serum total testosterone level is independently associated with NAFLD regardless of visceral adipose tissue and insulin resistance (Völzke et al. 2010, Kim et al. 2012). In our study, consistent with previous findings, we could measure serum testosterone in 76 patients (28 patients with NAFLD and 48 patients without NAFLD) after excluding patients treated with androgen deprivation therapy (ADT). The NAFLD group showed significantly lower testosterone levels ( 4.0 vs $4.9 \mathrm{ng} / \mathrm{ml} ; P=0.01$ ) compared with the non-NAFLD group. Contrary to the expectation, serum testosterone level (HR, 1.04; 95\% CI, $0.70-1.55 ; P=0.85)$, when treated as a continuous variable, was not an independent predictor of BCR. However, it is still unclear whether testosterone is

Published by Bioscientifica Ltd. 
Table 3 Univariate and multivariate analyses of factors associated with biochemical recurrence after radical prostatectomy

\begin{tabular}{|c|c|c|c|c|c|c|c|c|c|c|c|c|}
\hline & \multicolumn{6}{|c|}{ Training set $(n=147)$} & \multicolumn{6}{|c|}{ Validation set $(n=146)$} \\
\hline & \multicolumn{3}{|c|}{ Univariate analysis } & \multicolumn{3}{|c|}{ Multivariate analysis ${ }^{a, b}$} & \multicolumn{3}{|c|}{ Univariate analysis } & \multicolumn{3}{|c|}{ Multivariate analysis ${ }^{a, b}$} \\
\hline & $\mathrm{HR}$ & $95 \% \mathrm{Cl}$ & $P$ & $\begin{array}{c}\text { Adjusted } \\
\text { HR }\end{array}$ & $95 \% \mathrm{Cl}$ & $P$ & $\mathrm{HR}$ & $95 \% \mathrm{Cl}$ & $P$ & $\begin{array}{c}\text { Adjusted } \\
\text { HR }\end{array}$ & $95 \% \mathrm{Cl}$ & $P$ \\
\hline BMI & 0.91 & $0.88-1.15$ & 0.91 & & & & 1.02 & $0.91-1.14$ & 0.77 & & & \\
\hline BMI & & & - & & & & & & - & & & \\
\hline$<23$ & 1.00 & - & - & & & & 1.00 & & - & & & \\
\hline $23-24.9$ & 1.23 & $0.51-2.96$ & 0.64 & & & & 1.15 & $0.51-2.60$ & 0.74 & & & \\
\hline$>25$ & 1.06 & $0.48-2.45$ & 0.89 & & & & 0.91 & $0.40-2.05$ & 0.81 & & & \\
\hline Age & 0.97 & $0.93-1.02$ & 0.26 & & & & 1.01 & $0.96-1.07$ & 0.64 & & & \\
\hline DM & 0.62 & $0.22-1.77$ & 0.62 & & & & 0.73 & $0.26-2.08$ & 0.56 & & & \\
\hline $\begin{array}{l}\text { Metabolic } \\
\text { syndrome }^{c}\end{array}$ & 1.34 & $0.51-3.48$ & 0.55 & & & & 0.38 & $0.09-1.61$ & 0.19 & & & \\
\hline Surgery & & & 0.23 & & & & & & 0.80 & & & \\
\hline Open & 1.00 & - & - & & & & 1.00 & - & - & & & \\
\hline Laparoscopic & 0.61 & $0.28-1.37$ & - & & & & 0.91 & $0.42-1.95$ & - & & & \\
\hline NAFLD & 0.33 & $0.13-0.86$ & 0.02 & 0.36 & $0.14-0.97$ & 0.04 & 0.22 & $0.08-0.61$ & 0.004 & 0.17 & $0.06-0.49$ & 0.001 \\
\hline $\begin{array}{l}\text { Preoperative PSA } \\
\text { level }\end{array}$ & 1.01 & $0.98-1.04$ & 0.44 & & & & 1.01 & $0.99-1.04$ & 0.34 & & & \\
\hline Pathological GSC & & & - & & & & & & - & & & \\
\hline$<7$ & 1.00 & - & - & 1.00 & - & - & 1.00 & - & - & 1.00 & & \\
\hline 7 & 3.01 & $1.13-8.03$ & 0.03 & 3.22 & $1.21-8.59$ & 0.02 & 2.59 & $0.89-7.58$ & 0.08 & 1.99 & $0.67-5.86$ & 0.21 \\
\hline$>7$ & 8.39 & $2.64-26.68$ & $<0.001$ & 6.93 & $2.16-22.16$ & 0.001 & 6.11 & $1.94-19.18$ & 0.002 & 4.44 & $1.39-14.21$ & 0.01 \\
\hline $\begin{array}{l}\text { Pathological } \\
\text { stage }\end{array}$ & & & 0.09 & & & 0.62 & & & 0.01 & & & 0.63 \\
\hline pT2 & 1.00 & - & - & 1.00 & - & & 1.00 & - & - & 1.00 & - & \\
\hline pT3 & 1.84 & $0.92-3.71$ & - & 1.24 & $0.54-2.84$ & & 2.49 & $1.28-4.84$ & - & 1.21 & $0.56-2.61$ & \\
\hline $\begin{array}{l}\text { Positive surgical } \\
\text { margin }\end{array}$ & 1.91 & $0.95-3.82$ & 0.07 & 1.34 & $0.58-3.08$ & 0.49 & 2.76 & $1.41-5.40$ & 0.003 & 3.03 & $1.52-6.01$ & 0.002 \\
\hline $\begin{array}{l}\text { Extracapsular } \\
\text { extension }\end{array}$ & 1.92 & $0.95-3.87$ & 0.07 & & & & 2.63 & $1.35-5.10$ & 0.004 & & & \\
\hline $\begin{array}{l}\text { Invasion seminal } \\
\text { vesicles }\end{array}$ & 2.80 & $1.21-6.48$ & 0.02 & & & & 2.00 & $0.83-4.82$ & 0.12 & & & \\
\hline $\begin{array}{l}\text { Positive lymph } \\
\text { nodes }^{\mathrm{d}}\end{array}$ & 2.78 & $0.84-9.18$ & 0.09 & 1.00 & $0.24-4.14$ & 1.00 & 0.70 & $0.10-5.13$ & 0.73 & & & \\
\hline
\end{tabular}

DM, diabetes mellitus; NAFLD, nonalcoholic fatty liver disease; PSA, prostate-specific antigen; GSc, Gleason score.

a Variables in the multivariate model are adjusted for each other.

${ }^{b}$ Replacing pathological stage by extracapsular extension and seminal vesicle invasion in the multivariate model resulted in adjusted hazards ratio $(95 \% \mathrm{Cl})$ of $1.24(0.50-3.06, P=0.65)$ for extracapsular extension and $1.11(0.35-3.52, P=0.87)$ for seminal vesicle invasion in the training set and $1.21(0.56-2.61$, $P=0.63)$ for extracapsular extension and $0.81(0.30-2.20, P=0.68)$ for seminal vesicle invasion in the validation set, while the adjusted hazards ratios for the remaining variables hardly changed.

'Missing $n=46$ in the training set and 36 in the validation set because of unknown status of metabolic syndrome.

${ }^{\mathrm{d}}$ The reference category is no lymph node dissection performed or no positive lymph nodes.

involved in the initiation of prostate cancer or testosterone therapy increases the risk of prostate cancer. A collaborative analysis of 18 prospective studies found that the risk of prostate cancer is irrelevant to serum concentrations of testosterone, calculated free testosterone, dihydrotestosterone, or any other sex steroid tested (Roddam et al. 2008). In addition, a meta-analysis of testosterone trials failed to show an increased risk of prostate cancer with testosterone therapy (Fernández-Balsells et al. 2010). This lack of correlation of testosterone with prostate cancer risk has led to the proposal of the so-called 'saturation model'. According to this model, a saturation point of circulating testosterone at the nearcastrate range exists that saturates the target receptor. Above this point, the prostate cancer will no longer respond to further increases in circulating levels of testosterone, whereas below this point the androgenic response of prostate cancer will decrease as circulating levels of testosterone decreases (Morgentaler \& Traish 2009). Although the saturation model is currently unproven and further research is needed, this model could explain the undefined detrimental effect of testosterone replacement therapy and the therapeutic effect of ADT on established prostate cancer. In the subgroup analysis according to D'Amico risk stratification, we found that patients belonged to the D'Amico high-risk group showed significant association between NAFLD and prostate cancer BCR; however, patients belonged to the low or intermediate group failed to show statistically significant results. The D'Amico high-risk group received adjuvant treatments with ADT ( \pm radiation therapy) after radical prostatectomy more frequently (39.4 vs $16.5 \%$; $P<0.001)$ than the $\mathrm{D}^{\prime}$ Amico low-to-intermediate risk group. Statistically different results with NAFLD and 


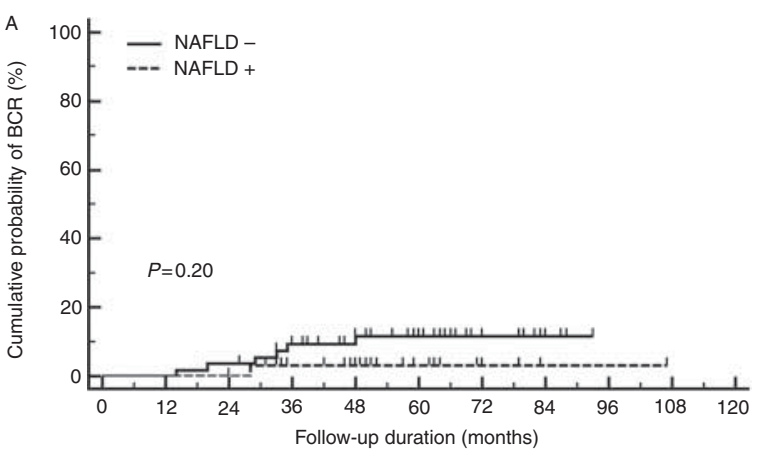

Number at risk

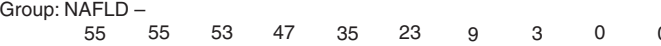
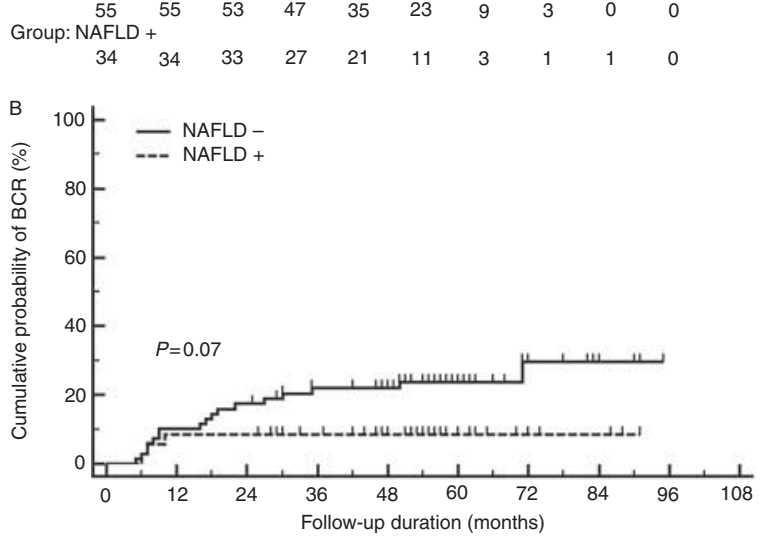

Number at risk

Group: NAFLD -

$\begin{array}{lllllllll}69 & 62 & 57 & 50 & 41 & 18 & 7 & 3 & 0\end{array}$

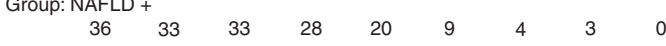

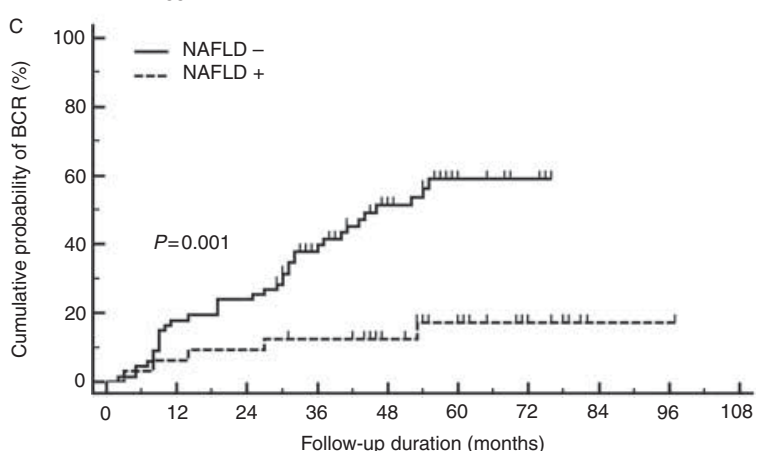

Number at risk

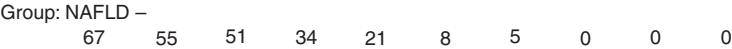

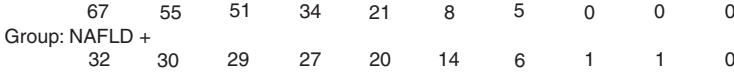

Figure 2

Time-to-BCR based on D'Amico risk group. (A) D'Amico low-risk group. (B) D'Amico intermediate risk group. (C) D'Amico high-risk group.

prostate cancer BCR according to D'Amico risk group could be explained by differences in the serum testosterone level depending on the presence of NAFLD and the frequency of ADT administration. Low serum testosterone levels in NAFLD and more frequent administration of ADT in the D'Amico high-risk group might intensify the therapeutic effect of ADT, which resulted in significantly longer time-to-BCR in the D'Amico high-risk patients with NAFLD compared with patients without NAFLD; however no statistically significant results were reported in the D'Amico low-or intermediate-risk patients. From these findings, it can be inferred that low serum testosterone levels in NAFLD could be another possible link between prostate cancer BCR and NAFLD.

Besides the relationship between NAFLD and prostate cancer BCR, which has not previously been evaluated, our findings are consistent with previous studies. Overall 5-year BCR-free survival rate was quite similar to previous studies which reported ranges from 70 to $87 \%$ (Han et al. 2001, Chun et al. 2006, Porter et al. 2006, Magheli et al. 2008). In regard to predictive factors of prostate cancer BCR, higher preoperative PSA level, higher GSc, advanced tumor stage, particularly with regard to seminal vesicle and/or lymph node invasion, and positive surgical margin have been generally reported to increase the risk of BCR (Han et al. 2001, Chun et al. 2006, Porter et al. 2006). Also in this study, pathological GSc and positive surgical margin were independent predictors for BCR. Although the relationship between obesity and prostate cancer, especially BCR after treatment for localized prostate cancer, has remained unclear, several prior studies failed to find a significant association between BMI and prostate cancer BCR after prostatectomy (Van Roermund et al. 2009, Lee et al. 2011, Tomaszewski et al. 2013). In contrast to the result from the previous studies indicating about the effect of DM on prostate cancer BCR, the present study failed to demonstrate the reduced risk of prostate cancer BCR in diabetic patients. As the duration of DM was not evaluated in the present study, this could be explained by

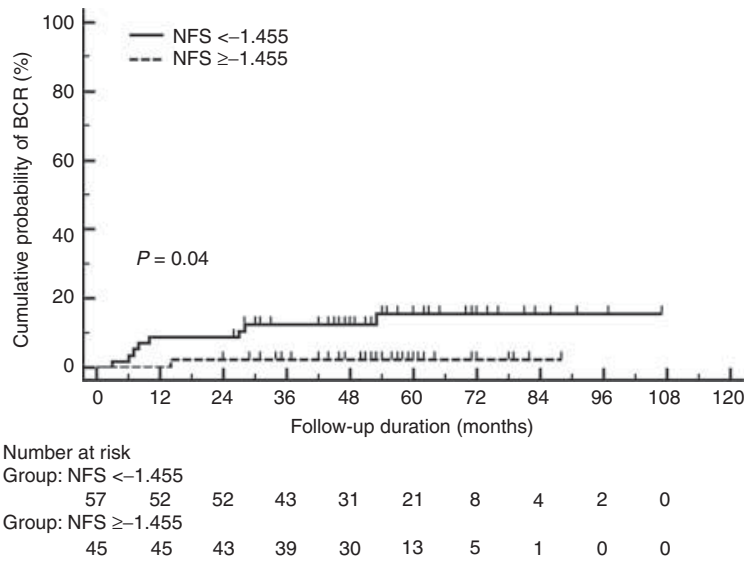

Figure 3

Time-to-BCR based on the NAFLD fibrosis score.

Published by Bioscientifica Ltd. 
earlier studies which reported that prostate cancer risk is not reduced in the incipient time since DM diagnosis (Rodriguez et al. 2005, Kasper et al. 2009).

Our study has several limitations. First, we provided cross-validation results using data from two university affiliated hospitals of external validation results. At first, we were planning to externally validate the result of one hospital by that of the other hospital. However, the baseline characteristics (i.e., kind of surgical treatment) of the patients between two centers were quite different; thus, we used cross-validation after mixing and randomizing the data. Second, we used US or unenhanced CT as the mode of diagnosis for NAFLD, while liver biopsy is regarded as the gold standard. Furthermore, without liver biopsy, it is impossible to characterize liver histology such as degree of fibrosis and distinguish between nonalcoholic fatty liver and nonalcoholic steatohepatitis because nonalcoholic steatohepatitis can progress to cirrhosis, liver failure, and liver cancer and increase hepatic and extrahepatic morbidity and mortality (Chalasani et al. 2012). However, a meta-analysis from 46 articles comparing various imaging modalities to liver biopsy for diagnosis of NAFLD concluded that mean sensitivity estimates for US and CT were 73.3-90.5 and 46.1-72.0\%, respectively, and mean specificity range were $69.6-85.2$ and 88.1-94.6\% respectively (Bohte et al. 2011). Specificity, sensitivity, positive predictive value, and negative predictive value of unenhanced CT liver attenuation alone with threshold of $48 \mathrm{HU}$ for diagnosis of NAFLD used in this study were 100, 53.8, 100, and 93.9\% respectively; these values are highly specific for diagnosing hepatic steatosis (Pickhardt et al. 2012). From these findings, US or unenhanced CT could be the diagnostic test of choice for NAFLD instead of liver biopsy, which has well-established drawbacks regarding its invasiveness and sampling error due to small sample size and inter-observer variability (Bravo et al. 2001). In terms of liver fibrosis, a metaanalysis from 13 studies consisting of 3064 patients documented that NAFLD fibrosis score has an AUROC of 0.85 for predicting advanced fibrosis and a score $<-1.455$ had $90 \%$ sensitivity and $60 \%$ specificity to exclude advanced fibrosis (Musso et al. 2011), which was used in this study instead of liver biopsy. In addition, the retrospective design and relatively small number of NAFLD patients may represent the limitations of our study. However, the clear inclusion and exclusion criteria might counteract this weak point. Another limitation is that many patients were excluded from the final analyses because of feasibility to diagnose NAFLD, with possible selection bias. In this study, actually, there were a number of patients diagnosed with NAFLD and prostate cancer through medical checkups. The mean age was lower in patients with NAFLD compared with patients without NAFLD. From this, it can be implied that it is more likely that an obese patient with a higher possibility of NAFLD is prone to receive early medical checkup, compared with the non-obese person. This phenomenon is likely to be related to concern for health and good compliance, thus affecting the good prognosis of prostate cancer.

In summary, the results of our study have shown that NAFLD may play a protective role against BCR after radical prostatectomy for prostate cancer. In addition, the protective role against BCR has strengthened as NAFLD progresses to advanced fibrosis. Further studies are warranted to elucidate the mechanism of the protective effect against prostate cancer presented above in patients with NAFLD.

\section{Declaration of interest}

The authors declare that there is no conflict of interest that could be perceived as prejudicing the impartiality of the research reported.

\section{Funding}

This research did not receive any specific grant from any funding agency in the public, commercial or not-for-profit sector.

\section{Acknowledgements}

The authors thank Jeong-ju Yoo, Minjong Lee, Yuri Cho, and Dong Hyeon Lee for sharing their knowledge and ideas.

\section{References}

Albanes D, Weinstein SJ, Wright ME, Männistö S, Limburg PJ, Snyder K \& Virtamo J 2009 Serum insulin, glucose, indices of insulin resistance, and risk of prostate cancer. Journal of the National Cancer Institute $\mathbf{1 0 1}$ 1272-1279. (doi:10.1093/jnci/djp260)

Angulo P 2002 Nonalcoholic fatty liver disease. New England Journal of Medicine 346 1221-1231. (doi:10.1056/NEJMra011775)

Angulo P, Hui JM, Marchesini G, Bugianesi E, George J, Farrell GC, Enders F, Saksena S, Burt AD \& Bida JP 2007 The NAFLD fibrosis score: a noninvasive system that identifies liver fibrosis in patients with NAFLD. Hepatology 45 846-854. (doi:10.1002/hep.21496)

Arturi F, Succurro E, Procopio C, Pedace E, Mannino GC, Lugarà M, Procopio T, Andreozzi F, Sciacqua A \& Hribal ML 2011 Nonalcoholic fatty liver disease is associated with low circulating levels of insulin-like growth factor-I. Journal of Clinical Endocrinology and Metabolism 96 E1640-E1644. (doi:10.1210/jc.2011-1227)

Bohte AE, van Werven JR, Bipat S \& Stoker J 2011 The diagnostic accuracy of US, CT, MRI and 1H-MRS for the evaluation of hepatic steatosis compared with liver biopsy: a meta-analysis. European Radiology 21 87-97. (doi:10.1007/s00330-010-1905-5)

Bravo AA, Sheth SG \& Chopra S 2001 Liver biopsy. New England Journal of Medicine 344 495-500. (doi:10.1056/NEJM200102153440706)

Published by Bioscientifica Ltd. 
Cao Y \& Ma J 2011 Body mass index, prostate cancer-specific mortality, and biochemical recurrence: a systematic review and meta-analysis. Cancer Prevention Research 4 486-501. (doi:10.1158/1940-6207.CAPR-10-0229)

Chalasani N, Younossi Z, Lavine JE, Diehl AM, Brunt EM, Cusi K, Charlton M \& Sanyal AJ 2012 The diagnosis and management of non-alcoholic fatty liver disease: practice Guideline by the American Association for the Study of Liver Diseases, American College of Gastroenterology, and the American Gastroenterological Association. Hepatology 55 2005-2023. (doi:10.1002/hep.25762)

Chun FK-H, Graefen M, Zacharias M, Haese A, Steuber T, Schlomm T, Walz J, Karakiewicz PI \& Huland H 2006 Anatomic radical retropubic prostatectomy - long-term recurrence-free survival rates for localized prostate cancer. World Journal of Urology 24 273-280. (doi:10.1007/ s00345-006-0058-2)

D'Amico AV, Whittington R, Malkowicz SB, Schultz D, Blank K, Broderick GA, Tomaszewski JE, Renshaw AA, Kaplan I \& Beard CJ 1998 Biochemical outcome after radical prostatectomy, external beam radiation therapy, or interstitial radiation therapy for clinically localized prostate cancer. Journal of the American Medical Association 280 969-974. (doi:10.1001/ jama.280.11.969)

De Nunzio C, Aronson W, Freedland SJ, Giovannucci E \& Parsons JK 2012 The correlation between metabolic syndrome and prostatic diseases. European Urology 61 560-570. (doi:10.1016/j.eururo.2011.11.013)

DiGiovanni J, Kiguchi K, Frijhoff A, Wilker E, Bol DK, Beltrán L, Moats S, Ramirez A, Jorcano J \& Conti C 2000 Deregulated expression of insulinlike growth factor 1 in prostate epithelium leads to neoplasia in transgenic mice. PNAS 97 3455-3460. (doi:10.1073/pnas.97.7.3455)

Edge SB \& Compton CC 2010 The American Joint Committee on Cancer: the 7th edition of the AJCC cancer staging manual and the future of TNM. Annals of Surgical Oncology 17 1471-1474. (doi:10.1245/s10434010-0985-4)

Expert Panel on Detection, Evaluation, and Treatment of High Blood Cholesterol in Adults 2001 Executive Summary of The Third Report of The National Cholesterol Education Program (NCEP) Expert Panel on Detection, Evaluation, And Treatment of High Blood Cholesterol In Adults (Adult Treatment Panel III). Journal of the American Medical Association 285 2486-2497. (doi:10.1001/jama.285.19.2486)

Fernández-Balsells MM, Murad MH, Lane M, Lampropulos JF, Albuquerque F, Mullan RJ, Agrwal N, Elamin MB, Gallegos-Orozco JF \& Wang AT 2010 Adverse effects of testosterone therapy in adult men: a systematic review and meta-analysis. Journal of Clinical Endocrinology and Metabolism 95 2560-2575. (doi:10.1210/jc.2009-2575)

Fusco A, Miele L, D’Uonnolo A, Forgione A, Riccardi L, Cefalo C, Barini A, Bianchi A, Giampietro A \& Cimino V 2012 Nonalcoholic fatty liver disease is associated with increased GHBP and reduced GH/IGF-I levels. Clinical Endocrinology 77 531-536. (doi:10.1111/j.1365-2265.2011. 04291.x)

Håheim LL, Wisløff T, Holme I \& Nafstad P 2006 Metabolic syndrome predicts prostate cancer in a cohort of middle-aged Norwegian men followed for 27 years. American Journal of Epidemiology 164 769-774. (doi:10.1093/aje/kwj284)

Han M, Partin AW, Pound CR, Epstein JI \& Walsh PC 2001 Long-term biochemical disease-free and cancer-specific survival following anatomic radical retropubic prostatectomy: the 15-year Johns Hopkins experience. Urologic Clinics of North America 28 555-565. (doi:10.1016/ S0094-0143(05)70163-4)

Hsing AW, Sakoda LC \& Chua SC 2007 Obesity, metabolic syndrome, and prostate cancer. American Journal of Clinical Nutrition 86 843S-857S.

Jones JI \& Clemmons DR 1995 Insulin-like growth factors and their binding proteins: biological actions. Endocrine Reviews 16 3-34.

Kasper JS \& Giovannucci E 2006 A meta-analysis of diabetes mellitus and the risk of prostate cancer. Cancer Epidemiology, Biomarkers \& Prevention 15 2056-2062. (doi:10.1158/1055-9965.EPI-06-0410)

Kasper JS, Liu Y \& Giovannucci E 2009 Diabetes mellitus and risk of prostate cancer in the health professionals follow-up study. International Journal of Cancer 124 1398-1403. (doi:10.1002/ijc.24044)

http://erc.endocrinology-journals.org DOI: $10.1530 /$ ERC-14-0036
(C) 2014 Society for Endocrinology Printed in Great Britain
Kim HJ, Kim HJ, Lee KE, Kim DJ, Kim SK, Ahn CW, Lim S-K, Kim KR, Lee HC \& Huh KB 2004 Metabolic significance of nonalcoholic fatty liver disease in nonobese, nondiabetic adults. Archives of Internal Medicine 164 2169. (doi:10.1001/archinte.164.19.2169)

Kim S, Kwon H, Park J-H, Cho B, Kim D, Oh S-W, Lee CM \& Choi H-C 2012 A low level of serum total testosterone is independently associated with nonalcoholic fatty liver disease. BMC Gastroenterology 1269. (doi:10.1186/1471-230X-12-69)

Lawrence Y, Morag O, Benderly M, Boyko V, Novikov I, Dicker A, Goldbourt U, Behar S, Barchana M \& Wolf I 2013 Association between metabolic syndrome, diabetes mellitus and prostate cancer risk. Prostate Cancer and Prostatic Diseases 16 181-186. (doi:10.1038/pcan.2012.54)

Lee SE, Lee WK, Jeong MS, Abdullajanov M, Kim DS, Park HZ, Jeong SJ, Yoon CY, Byun SS \& Choe G 2011 Is body mass index associated with pathological outcomes after radical prostatectomy in Korean men? BJU International 107 1250-1256. (doi:10.1111/j.1464-410X.2010. 09592.x)

Magheli A, Rais-Bahrami S, Trock BJ, Humphreys EB, Partin AW, Han M \& Gonzalgo ML 2008 Impact of body mass index on biochemical recurrence rates after radical prostatectomy: an analysis utilizing propensity score matching. Urology 72 1246. (doi:10.1016/j.urology. 2008.01.052)

Marchesini G, Brizi M, Morselli-Labate AM, Bianchi G, Bugianesi E, McCullough AJ, Forlani G \& Melchionda N 1999 Association of nonalcoholic fatty liver disease with insulin resistance. American Journal of Medicine 107 450-455. (doi:10.1016/S0002-9343(99)00271-5)

Martin RM, Vatten L, Gunnell D, Romundstad P \& Nilsen TI 2009 Components of the metabolic syndrome and risk of prostate cancer: the HUNT 2 cohort, Norway. Cancer Causes \& Control 20 1181-1192. (doi:10.1007/s10552-009-9319-x)

Morgentaler A \& Traish AM 2009 Shifting the paradigm of testosterone and prostate cancer: the saturation model and the limits of androgendependent growth. European Urology 55 310-321. (doi:10.1016/j. eururo.2008.09.024)

Musso G, Gambino R, Cassader M \& Pagano G 2011 Meta-analysis: natural history of non-alcoholic fatty liver disease (NAFLD) and diagnostic accuracy of non-invasive tests for liver disease severity. Annals of Medicine 43 617-649. (doi:10.3109/07853890.2010.518623)

Park SH, Jeon WK, Kim SH, Kim HJ, Park DI, Cho YK, Sung IK, Sohn CI, Keum DK \& Kim BI 2006 Prevalence and risk factors of non alcoholic fatty liver disease among Korean adults. Journal of Gastroenterology and Hepatology 21 138-143. (doi:10.1111/j.1440-1746.2005.04086.x)

Pickhardt PJ, Park SH, Hahn L, Lee S-G, Bae KT \& Yu ES 2012 Specificity of unenhanced CT for non-invasive diagnosis of hepatic steatosis: implications for the investigation of the natural history of incidental steatosis. European Radiology 22 1075-1082. (doi:10.1007/s00330-0112349-2)

Porter CR, Kodama K, Gibbons RP, Correa R Jr, Chun FK, Perrotte P \& Karakiewicz PI 2006 25-year prostate cancer control and survival outcomes: a 40-year radical prostatectomy single institution series. Journal of Urology 176 569-574. (doi:10.1016/j.juro.2006.03.094)

Pound CR, Partin AW, Eisenberger MA, Chan DW, Pearson JD \& Walsh PC 1999 Natural history of progression after PSA elevation following radical prostatectomy. Journal of the American Medical Association 281 1591-1597. (doi:10.1001/jama.281.17.1591)

Roddam A, Allen N, Appleby P \& Key T 2008 Endogenous sex hormones and prostate cancer: a collaborative analysis of 18 prospective studies. Journal of the National Cancer Institute 100 170-183. (doi:10.1093/jnci/ djm323)

Rodriguez C, Patel AV, Mondul AM, Jacobs EJ, Thun MJ \& Calle EE 2005 Diabetes and risk of prostate cancer in a prospective cohort of US men. American Journal of Epidemiology 161 147-152. (doi:10.1093/aje/ kwh334)

Rowlands MA, Gunnell D, Harris R, Vatten LJ, Holly JM \& Martin RM 2009 Circulating insulin-like growth factor peptides and prostate cancer risk:

Published by Bioscientifica Ltd. 
a systematic review and meta-analysis. International Journal of Cancer 124 2416-2429. (doi:10.1002/ijc.24202)

Saadeh S, Younossi ZM, Remer EM, Gramlich T, Ong JP, Hurley M, Mullen KD, Cooper JN \& Sheridan MJ 2002 The utility of radiological imaging in nonalcoholic fatty liver disease. Gastroenterology 123 745-750. (doi:10.1053/gast.2002.35354)

Svensson J, Kindblom J, Shao R, Movérare-Skrtic S, Lagerquist MK, Andersson N, Sjögren K, Venken K, Vanderschueren D \& Jansson J-O 2008 Liver-derived IGF1 enhances the androgenic response in prostate. Journal of Endocrinology 199 489-497. (doi:10.1677/JOE-08-0406)

Tande AJ, Platz EA \& Folsom AR 2006 The metabolic syndrome is associated with reduced risk of prostate cancer. American Journal of Epidemiology 164 1094-1102. (doi:10.1093/aje/kwj320)

Tomaszewski JJ, Chen Y-F, Bertolet M, Ristau BT, Woldemichael E \& Nelson JB 2013 Obesity is not associated with aggressive pathologic features or biochemical recurrence after radical prostatectomy. Urology 81 992-996. (doi:10.1016/j.urology.2012.10.080)
Torres DM \& Harrison SA 2008 Diagnosis and therapy of nonalcoholic steatohepatitis. Gastroenterology 134 1682-1698. (doi:10.1053/j.gastro. 2008.02.077)

Van Gaal LF, Mertens IL \& Christophe E 2006 Mechanisms linking obesity with cardiovascular disease. Nature $\mathbf{4 4 4}$ 875-880. (doi:10.1038/ nature05487)

Van Roermund JG, Kok DE, Wildhagen MF, Kiemeney LA, Struik F, Sloot S, Van Oort IM, Hulsbergen-van de Kaa CA, Van Leenders GJ \& Bangma CH 2009 Body mass index as a prognostic marker for biochemical recurrence in Dutch men treated with radical prostatectomy. BJU International 104 321-325. (doi:10.1111/j.1464-410X.2009. 08404.x)

Völzke H, Aumann N, Krebs A, Nauck M, Steveling A, Lerch MM, Rosskopf D \& Wallaschofski H 2010 Hepatic steatosis is associated with low serum testosterone and high serum DHEAS levels in men. International Journal of Andrology 33 45-53. (doi:10.1111/j.1365-2605. 2009.00953.x)

Received in final form 24 January 2014

Accepted 28 January 2014

Made available online as an Accepted Preprint

30 January 2014 